\title{
Synthesis and Characterization of Optically Active Polyesters from Chiral 1,3-Diols and Aromatic Dicarboxylic Acid Chlorides
}

\author{
Tohru KoBAYASHI, Masa-aki KAKIMOTO*, and Yoshio IMAI ${ }^{*, \dagger}$ \\ Takasago International Corporation, \\ Kamata, Ohta-ku, Tokyo 144, Japan \\ * Department of Organic and Polymeric Materials, \\ Tokyo Institute of Technology, \\ Meguro-ku, Tokyo 152, Japan
}

(Received January 11, 1993)

\begin{abstract}
Optically active polyesters were synthesized from chiral $(2 R, 4 R)$-pentane-2,4-diol or its analogues and various aromatic diacid chlorides in refluxing 1,2-dichloroethane in the presence of pyridine. The resulting polyesters had inherent viscosities of $0.22-0.57 \mathrm{dlg}^{-1}$, and specific rotation from $+4^{\circ}$ to $-421^{\circ}$. The glass transition temperatures of the polymers were in the range from $66^{\circ} \mathrm{C}$ to $147^{\circ} \mathrm{C}$ and their initial decomposition temperatures were around $280^{\circ} \mathrm{C}$. No remarkable difference in thermal behavior was observed between the optically active polyesters and optically inactive polymers derived from the corresponding racemic diols.
\end{abstract}

KEY WORDS Optically Active Polyesters / Chiral 1,3-Diols / Dichroic

Absorption / Thermal Behavior /

Polyesters having asymmetric carbons in their main chains have been synthesized and characterized by several authors in order to investigate the influence of the chirality to the physical properties of the polymers such as melting point, glass transition temperature, crystallinity, solubility in various solvents, and mechanical properties. ${ }^{1}$ Recently much interusts have been paid to prepare optically active polymers having various functionalities and high performances (liquid crystaliline polymers, ${ }^{2}$ HPLC chiral stationary phases, ${ }^{3}$ etc.). In most cases, however, only the derivatives of naturally occuring compounds are sources for optically active units of the polymers. The preparation of optically active monomers by asymmetric synthesis is interesting, because a variety of new types of optically pure

Table I. Properties of chiral diols I

\begin{tabular}{|c|c|c|c|c|c|c|}
\hline $\begin{array}{l}\text { Chiral } \\
\text { diols }\end{array}$ & $\mathrm{R}_{1}$ & $\mathrm{R}_{2}$ & Configuration & $\frac{\mathrm{mp}}{{ }^{\circ} \mathrm{C}}$ & $\frac{e . e .^{\mathrm{a}}}{\%}$ & {$[\alpha]_{D}^{b}$} \\
\hline Ia & $\mathrm{CH}_{3}$ & $\mathrm{CH}_{3}$ & $2 R, 4 R$ & $46-47$ & $>99$ & -38.6 \\
\hline Ib & $\mathrm{C}_{6} \mathrm{H}_{5}$ & $\mathrm{CH}_{3}$ & $1 S, 3 R$ & $61-63$ & 94.2 & -78.3 \\
\hline Ic & $\mathrm{C}_{6} \mathrm{H}_{5}$ & $\mathrm{C}_{6} \mathrm{H}_{5}$ & $1 S, 3 S$ & $152-153$ & $>99$ & -55.2 \\
\hline
\end{tabular}

a Enantiomeric excess determined by HPLC analyses of the corresponding $(R)$ - $\alpha$-trifluoromethylphenylacethyl esters.

b Measured in chloroform at $25^{\circ} \mathrm{C}$.

$\dagger$ To whom corresponding should be addressed. 
monomers could be obtained in both antipodes. This article deals with the preparation and characterization of optically active polyesters from aromatic dicarboxylic acid chlorides and chiral diols which were derived by the
Ruthenium-BINAP-catalyzed asymmetric hydrogenation of the corresponding $\beta$-diketones (BINAP $=2,2^{\prime}$-bis(diphenylphosphino)-1, $1^{\prime}$ binaphtyl) (eq 1).

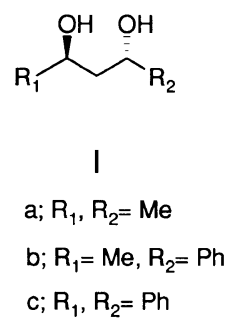

$+\quad$ ClOC-Ar-COCI

II

$$
\begin{aligned}
& \mathrm{a} ; \mathrm{Ar}=\text { - } \\
& \mathrm{b} ; \mathrm{Ar}=\mathrm{O} \\
& \mathrm{c} ; \mathrm{Ar}=\text { (O) }
\end{aligned}
$$

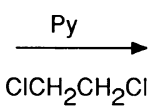

$\mathrm{d} ; \mathrm{Ar}=$ $\mathrm{e} ; \mathrm{Ar}=$

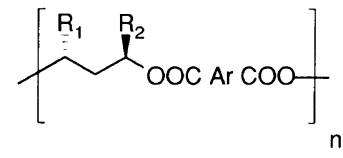

III

\section{EXPERIMENTAL}

\section{Measurements}

IR spectra were recorded on a JASCO IR-810 spectrophotometer. Both ${ }^{1} \mathrm{H}$ NMR and ${ }^{13} \mathrm{C}$ NMR spectra were measured on a Bruker AMX 400 spectrometer using tetramethylsilane as an internal standard, and chemical shifts are quoted in ppm. Optical rotation measurements were obtained on a JASCO DIP-360 spectrometer. Circular dichroism (CD) spectra and UV spectra were recorded on a JASCO J-500C spectropolarimeter and a Hitachi 330 spectrophotometer, respectively. Differential scanning calorimetry (DSC) and themogravimetry (TG) were performed with Shimadzu thermal analyzers DSC-41M and TGA-40M, respectively, and measurements were run at a heating rate of $10^{\circ} \mathrm{C} \mathrm{min}{ }^{-1}$ under nitrogen at a flow rate of $50 \mathrm{ml} \mathrm{min}^{-1}$. Weight-average molecular weight $\left(\bar{M}_{w}\right)$ and number-average molecular weight $\left(\bar{M}_{n}\right)$ were determined by means of gel permeation chromatography (GPC) on the basis of polystyrene calibration on a Hitachi apparatus (eluent, $\mathrm{CHCl}_{3}$ ).

\section{Chiral Diols}

Using $\mathrm{Ru}_{2} \mathrm{Cl}_{4}[(R)-\mathrm{BINAP}]_{2}\left(\mathrm{NEt}_{3}\right)$ as the catalyst for the asymmetric hydrogenation, chiral diols I were synthesized from the corresponding $\beta$-diketones by the similar procedure repored previously. ${ }^{4}(2 R, 4 R)$-Pentane-2,4-diol Ia and (1 $S, 3 R)$-1-phenylbutane-1,3diol Ib were purified by distillation followed by recrystallization from ether and hexane-ethyl acetate, respectively. (1S,3S)-1,3-Diphenylpropane-1,3-diol Ic was purified by recrystallization from 1,2-dichloroethane. Melting points, configuration, enantiomeric exess (e.e.), and specific rotation of purified diols are listed in Table I.

\section{(2RS,4RS)-Pentane-2,4-diol IVa and ( $1 R S, 3 R S)$ -}

\section{1,3-Diphenylpropane-1,3-diol IVb}

Equal amount of Ia and $(2 S, 4 S)$-pentane2,4-diol (prepared by the asymmetric hydrogenation of 2,4-pentanedione using $\mathrm{Ru}_{2} \mathrm{Cl}_{4}[(S)$ BINAP $]_{2}\left(\mathrm{NEt}_{3}\right)$ followed by recrystallization from ether, $>99 \%$ e.e., $[\alpha]_{\mathrm{D}}^{25}+41.6^{\circ}$ (c 1.05, $\left.\mathrm{CHCl}_{3}\right)$ was used as $(2 R S, 4 R S)$-pentane-2,4diol IVa.

(1 $R S, 3 R S)$-1,3-Diphenylpropane-1,3-diol IVb was synthesized as follows: To a solution of 1,3-diphenylpropane-1,3-dione (25.0 g, 0.111 $\mathrm{mol})$ in a mixture of methanol $(150 \mathrm{ml})$ and benzene $(150 \mathrm{ml})$ was added dropwise a solution of sodium borohydride $(5.0 \mathrm{~g}, 0.132$ $\mathrm{mol})$ in water $(50 \mathrm{ml})$ upon cooling with an ice bath. The mixture was stirred overnight at room temperature and refluxed for $10 \mathrm{~h}$, and 
then poured into water. Extraction with ether, drying on magnesium sulfate, evaporation of the solvents, followed by column chromatography (silica gel, eluent: hexane/ethyl acetate then methanol alone) gave a mixture of $(1 R S, 3 R S)$ - and (1RS,3SR)-diols. Recrystallization from a mixture of hexane and chloroform gave $8.4 \mathrm{~g}$ (33\%) of DL-diol IVb. $\mathrm{mp} 123-125^{\circ} \mathrm{C}$.

IR (K Br): 3400, 1455, 1402, 1063, 1036, 1024 , $766,756,700 \mathrm{~cm}^{-1}$.

${ }^{1} \mathrm{H}$ NMR $\left(\mathrm{CDCl}_{3}\right): 2.18(\mathrm{t}, J=5.5 \mathrm{~Hz}, 2 \mathrm{H})$, $2.75-3.00(\mathrm{br}, 2 \mathrm{H}), 4.97(\mathrm{t}, J=5.6 \mathrm{~Hz}, 2 \mathrm{H})$, $7.20-7.38(\mathrm{~m}, 10 \mathrm{H}) \mathrm{ppm}$.

Anal. Calcd for $\mathrm{C}_{15} \mathrm{H}_{10} \mathrm{O}_{2}: \mathrm{C}, 78.92 \% ; \mathrm{H}$, $7.06 \%$. Found: $\mathrm{C}, 78.65 \%$; H, $6.95 \%$.

\section{Materials}

Reagent-grade dicarboxylic acid chlorides such as terephthaloyl chloride (IIa) and isophthaloyl chloride (IIb) were purified by distillation under reduced pressure. 4,4'Biphenyldicarbonyl chloride (IIc), 4,4'-oxydi(benzoyl chloride) (IId), and 2,6-naphthalenedicarbonyl chloride (IIe) were prepared from the corresponding dicarboxylic acids and thionyl chloride. Compound IId was purified by distillation under reduced pressure, while IIc and IIe were purified by sublimation. 1,2-Dichloroethane and pyridine were distilled over phosphorus pentoxide and calcium hydride, respectively.

\section{Polymerization}

A typical example of the polymerization is described below.

\section{Polyester IIIa}

To a mixture of $1.00 \mathrm{~g}(9.6 \mathrm{mmol})$ of Ia and $2.00 \mathrm{~g}(25.3 \mathrm{mmol})$ of pyridine in 1,2-dichloroethane $(20 \mathrm{ml})$ was added portionwise $1.949 \mathrm{~g}(9.6 \mathrm{mmol})$ of terephthaloyl chloride (IIa) in a period of $5 \mathrm{~min}$. The reaction mixture was refluxed at $82^{\circ} \mathrm{C}$ for $10 \mathrm{~h}$ under nitrogen, and poured into $200 \mathrm{ml}$ of methanol. The precipitated polymer was collected by filtra- tion, washed with hot methanol, and dried under vacuum. The polymer weighed $2.20 \mathrm{~g}$ $(98 \%)$ and had an inherent viscosity of $0.56 \mathrm{dl} \mathrm{g}^{-1}$, measured at a concentration of $0.5 \mathrm{~g} \mathrm{dl}^{-1}$ in phenol-1,1,2,2- tetrachloroethane $(6: 4, \mathrm{v} / \mathrm{v})$ at $30^{\circ} \mathrm{C} .[\alpha]_{\mathrm{D}}^{25}-295^{\circ}\left(\right.$ c $\left.0.20, \mathrm{CHCl}_{3}\right)$.

IR (film): 2975, 2925, $1720(\mathrm{C}=\mathrm{O}), 1460$, $1405,1378,1350,1270,1100,1035,1018,875$, $755,718 \mathrm{~cm}^{-1}$.

${ }^{1} \mathrm{H}$ NMR $\left(\mathrm{CDCl}_{3}\right): 1.54(\mathrm{~d}, J=6.3 \mathrm{~Hz}, 6 \mathrm{H})$, $2.10(\mathrm{t}, J=6.4 \mathrm{~Hz}, 2 \mathrm{H}), 5.30$ (sextet, $J=6.3 \mathrm{~Hz}$, $2 \mathrm{H}), 8.00(\mathrm{~s}, 4 \mathrm{H}) \mathrm{ppm}$.

${ }^{13} \mathrm{C} \mathrm{NMR}\left(\mathrm{CDCl}^{3}\right): 20.9,42.5,69.0,129.5$, 134.3, $165.1 \mathrm{ppm}$.

Anal. Calcd for $\mathrm{C}_{13} \mathrm{H}_{14} \mathrm{O}_{4}: \mathrm{C}, 66.66 \% ; \mathrm{H}$, $6.02 \%$. Found: C, $66.29 \% ; \mathrm{H}, 6.11 \%$.

Other polyesters were synthesized by the similar procedure.

\section{RESULTS AND DISCUSSION}

\section{Polymer Synthesis}

The bulk polycondensation of $(2 R, 4 R)$ pentane-2,4-diol (Ia) with terephthaloyl chloride (IIa) by heating at $100^{\circ} \mathrm{C}$ under reduced pressure gave only low molecular weight polymer. We isolated compound $\mathbf{V}$ from the resulting mixture by silica gel column chromatography. This result indicated that some of the terminal secondary alcohols were chlorinated by hydrogen chloride generated during the polymerization, and hence this limited molecular weight of the resulting polymer.

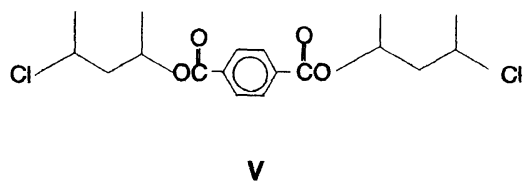

The polyesters with inherent viscosities of $0.22-0.57 \mathrm{dl} \mathrm{g}^{-1}$ were readily obtained by the solution polycondensation in refluxing 1,2dichloroethane in the presence of pyridine as a hydrogen chloride acceptor. The results of the synthesis of polyesters are summarized in Table II. The polymers had $\bar{M}_{n}$ of $7000-56000$ 
Table II. Synthesis of optically active and inactive polyesters

\begin{tabular}{|c|c|c|c|c|c|c|c|}
\hline \multicolumn{2}{|c|}{ Monomers } & \multicolumn{6}{|c|}{ Polymer } \\
\hline \multirow{2}{*}{ Diol } & \multirow{2}{*}{$\begin{array}{l}\text { Diacid } \\
\text { chloride }\end{array}$} & \multirow{2}{*}{ Code } & \multirow{2}{*}{$\begin{array}{c}\text { Yield } \\
\%\end{array}$} & \multirow{2}{*}{$\frac{\eta_{\mathrm{inh}}^{\mathrm{a}}}{\mathrm{dl} \mathrm{g}^{-1}}$} & \multirow{2}{*}{$\begin{aligned} & \bar{M}_{n}^{\mathrm{b}} \\
& \times 10^{-4}\end{aligned}$} & \multirow{2}{*}{$\frac{\bar{M}_{w}{ }^{\mathrm{b}}}{\times 10^{-4}}$} & \multirow{2}{*}{$\bar{M}_{w} / \bar{M}_{n}$} \\
\hline & & & & & & & \\
\hline Ia & IIa & IIIa & 98 & 0.56 & 5.0 & 6.4 & 1.3 \\
\hline Ia & IIb & IIIb & 92 & 0.47 & 3.6 & 5.0 & 1.4 \\
\hline Ia & IIc & IIIc & 89 & 0.43 & 1.7 & 3.5 & 2.1 \\
\hline Ia & IId & IIId & 98 & 0.57 & 3.0 & 5.2 & 1.7 \\
\hline Ia & IIe & IIIe & 86 & 0.22 & 0.7 & 1.4 & 2.0 \\
\hline Ib & IIa & IIIf & 94 & 0.36 & 1.4 & 3.4 & 2.4 \\
\hline Ic & IIa & IIIg & 80 & 0.41 & 2.9 & 4.8 & 1.7 \\
\hline IVa & IIa & VIa & 91 & 0.48 & 2.0 & 4.3 & 2.1 \\
\hline IVb & IIa & VIb & 82 & 0.37 & 1.5 & 3.6 & 2.4 \\
\hline
\end{tabular}

${ }^{a}$ Measured at a concentration of $0.5 \mathrm{~g} \mathrm{dl}^{-1}$ in phenol-1,1,2,2-tetrachloroethane $(6: 4, \mathrm{v} / \mathrm{v})$ at $30^{\circ} \mathrm{C}$.

b Determined by GPC on the basis of polystyrene calibration.

by GPC analyses based on standard polystyrene and the $\bar{M}_{w} / \bar{M}_{n}$ values were $1.3-2.4$. By the same manner for the syntheses of optically active polymers, we also prepared<smiles>[2H]C([2H])([2H])OC(=O)c1ccc(C(=O)Cl)cc1</smiles>

IV Ila optically inactive polyesters VIa and VIb by the reaction of terephtaloyl chloride with racemic diols IVa and IVb, respectively (eq 2), and the results are listed in Table II.

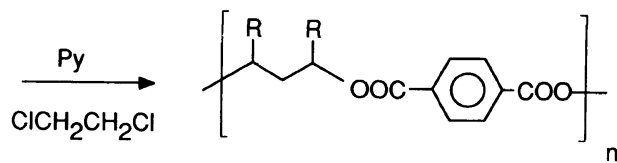

$$
\text { VI }
$$
$\mathrm{a} ; \mathrm{R}=\mathrm{Me}$
$\mathrm{b} ; \mathrm{R}=\mathrm{Ph}$

\section{Polymer Characterization}

The polyesters from chiral diols I had negative specific rotation values except for IIIg (Table III). We synthesized VII and VIII as model compounds for polymer IIIa.
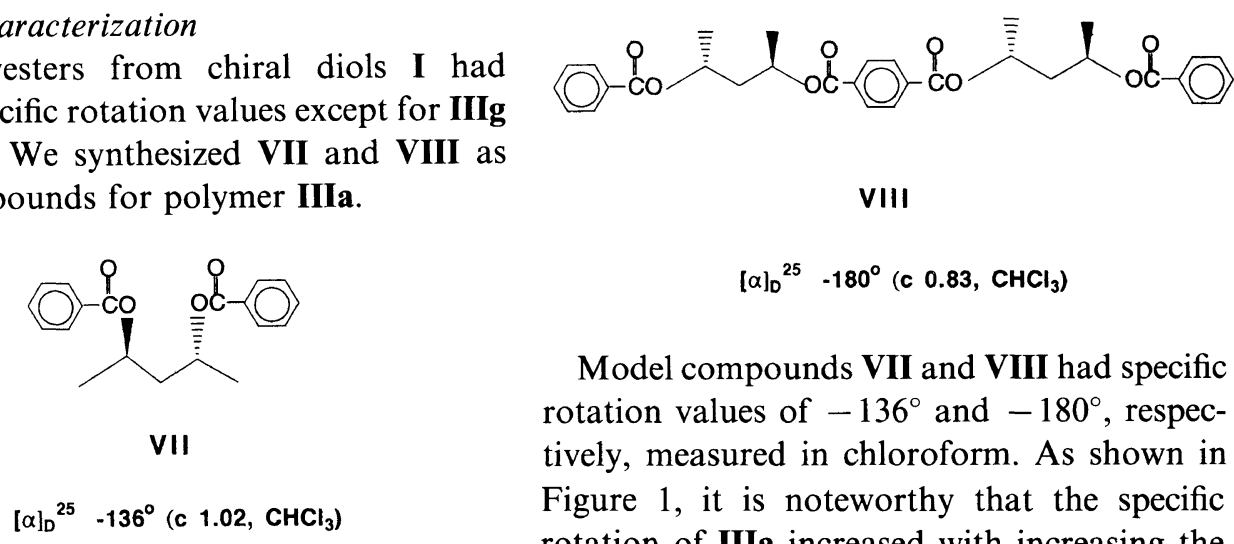

Model compounds VII and VIII had specific rotation values of $-136^{\circ}$ and $-180^{\circ}$, respectively, measured in chloroform. As shown in Figure 1, it is noteworthy that the specific rotation of IIIa increased with increasing the inherent viscosity, and saturated over around 


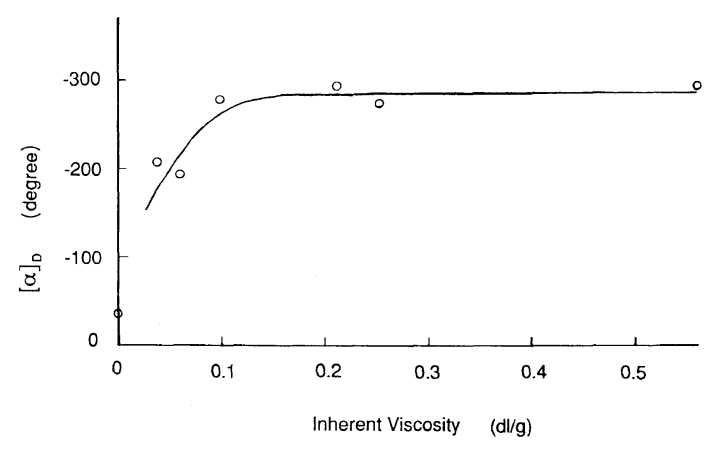

Figure 1. Relationship between inherent viscosity and specific rotation of polymer IIIa. Inherent viscosity; measured in phenol-,1,2,2-tetrachloroethane $(6: 4, \mathrm{v} / \mathrm{v})$ at a concentration of $0.5 \mathrm{~g} \mathrm{dl}^{-1}$ at $30^{\circ} \mathrm{C}$. Specific rotation, measured in $\mathrm{CHCl}_{3}$ at $25^{\circ} \mathrm{C}$.

\section{$0.1 \mathrm{dlg}^{-1}$.}

Figure 2 shows the CD and UV spectra of optically active polyester IIIa. These spectra indicated that the polymers had dichroic absorption from $280 \mathrm{~nm}$ to $220 \mathrm{~nm}$, characterized by negative and positive peaks. This suggests that the aromatic nuclei of the polymers are located in a chirally perturbed environment similar to other polyesters reported. ${ }^{5}$

Polymer IIIc, IIIe, IIIf, and IIIg whose aromatic rings are linearly bonded in the main chain gave similar CD behavior to that of IIIa in the UV absorption region based on $\pi \rightarrow \pi^{*}$ electronic transitions. The $\mathrm{CD}$ spectrum of polymer IIId showed relatively small positive peak compared with negative dichroic band, whereas no maximum peak was obtained for IIIb in the region between $220 \mathrm{~nm}$ and $300 \mathrm{~nm}$.

Optically active polymers IIIa-IIId having methyl side groups were soluble in chloroform, 1,2-dichloroethane, tetrahydrofuran (THF), toluene, and amide solvents, such as $N, N$ dimethylformamide, and $N$-methylpyrrolidone, but insoluble in dimethyl sulfoxide (DMSO) at room temperature. Polymers IIIf and IIIg having phenyl side groups were more readily soluble in these solvents, even in DMSO at room temperature, while polyester IIIe derived from 2,6-naphthalenedicarbonyl chlo-

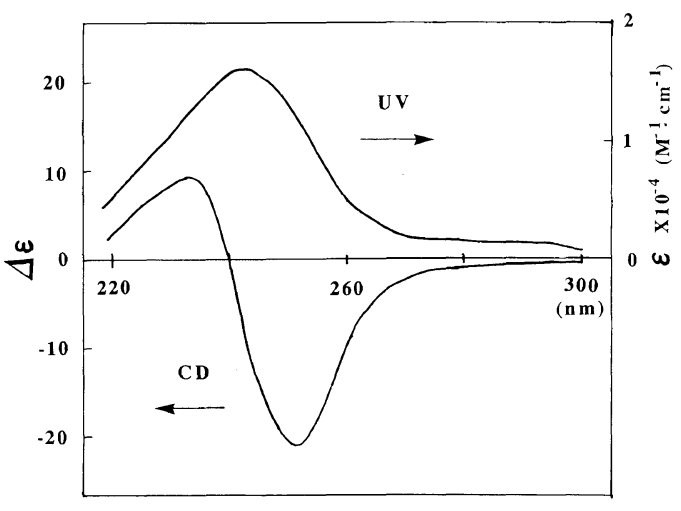

Figure 2. CD and UV spectra of polymer IIIa in dioxane dilute solution.

Table III. Optical rotation values and thermal behavior of polyesters

\begin{tabular}{|c|c|c|c|c|}
\hline \multirow{2}{*}{ Polymer } & {$[\alpha]_{\mathrm{D}}{ }^{\mathrm{a}}$} & $T_{\mathrm{g}}^{\mathrm{b}}$ & $T_{\mathrm{d}}^{\mathrm{c}}$ & $T_{10}^{\mathrm{d}}$ \\
\hline & degree & ${ }^{\circ} \mathrm{C}$ & ${ }^{\circ} \mathrm{C}$ & ${ }^{\circ} \mathrm{C}$ \\
\hline IIIa & -295 & 84 & 283 & 314 \\
\hline IIIb & -183 & 66 & 283 & 311 \\
\hline IIIc & -421 & 120 & 285 & 324 \\
\hline IIId & -284 & 100 & 282 & 323 \\
\hline IIIe & $-^{\mathbf{e}}$ & 111 & 277 & 316 \\
\hline IIIf & -99 & 113 & 241 & 268 \\
\hline IIIg & +4 & 147 & 276 & 307 \\
\hline VIa & 0 & 88 & 283 & 319 \\
\hline VIb & 0 & 149 & 272 & 294 \\
\hline
\end{tabular}

a Measured in chloroform at $25^{\circ} \mathrm{C}$.

b Determined by DSC in nitrogen at a heating rate of $10^{\circ} \mathrm{C} \mathrm{min} \mathrm{m}^{-1}$.

c $T_{\mathrm{d}}$ is the initial decomposition temperature measured by $\mathrm{TG}$ in nitrogen at a heating rate of $10^{\circ} \mathrm{C} \mathrm{min}-1$.

d $T_{10}$ is the temperature of $10 \%$ weight loss, measured by TG in nitrogen at a heating rate of $10^{\circ} \mathrm{C} \mathrm{min}^{-1}$.

e Only slightly soluble in chloroform.

ride was less soluble in THF, toluene, and DMSO. No remarkable difference of the solubility was observed between the optically active polyesters and the corresponding optically inactive polymers.

The thermal characterization was carried out by means of differential scanning calorimetry (DSC) and thermogravimetry (TG). The thermal behavior of the polyesters are listed in Table III. The glass transition temperatures 
$\left(T_{\mathrm{g}}\right)$ of the optically active polyesters were observed from $66^{\circ} \mathrm{C}$ to $147^{\circ} \mathrm{C}$ by DSC measurments. The results for polymers IIIa, IIIf, and IIIg indicated that the $T_{\mathrm{g}}$ increased with increasing the number of phenyl side groups. This phenomenon is explained in terms of increasing of rigidity caused by the introduction of phenyl group. The thermal decomposition temperature $\left(T_{\mathrm{d}}\right)$ of the optically active polymers started at around $280^{\circ} \mathrm{C}$ under nitrogen. No significant difference in thermal behavior ( $T_{\mathrm{g}}$ and $T_{\mathrm{d}}$ ) was observed between optically inactive polyesters VIa and VIb and the corresponding optically active polyesters.

\section{CONCLUSION}

We have synthesized optically active polyesters from chiral 2,4-pentanediol or its analogues and aromatic dicarboxylic acid chlorides in the presence of pyridine as a hydrogen chloride acceptor. The CD spectra of some of III showed dichroic absorption, characterized by negative and positive peaks. The $T_{\mathrm{g}}$ of the resulting polymers heightened with increasing the number of attached phenyl groups. The thermal properties and solubility of the optically inactive polyesters VIa and VIb did not differ significantly from those of the corresponding optically active polyesters.

\section{REFERENCES}

1. K. W. Doak and H. N. Campbell, J. Polym. Sci., 18, 215 (1955); J. Kleine and H. Kleine, Makromol. Chem., 30, 23 (1959); M. S. Toy, J. Polym. Sci., 5, 2481 (1967).

2. S. Uchida, K. Morita, K. Miyoshi, K. Hashimoto, and K. Kawasaki, Mol. Cryst. Liq. Cryst., 155, 93 (1988); A. C. Griffin, A. M. Bhatti, and R. S. L. Hung, ibid., 155, 129 (1988); H. Hara, T. Satoh, T. Toya, S. Iida, S. Orii, and J. Watanabe, Macromolecules, 21, 14 (1988).

3. S. G. Allenmark, "Chromatographic Enantioseparation; Methods and Applications," John Wiley \& Sons, New York, 1988; Y. Okamoto, CHEMTEC, 176, (1987).

4. M. Kitamura, T. Ohkuma, S. Inoue, N. Sayo, H. Kumobayashi, S. Akutagawa, T. Ohta, H. Takaya, and R. Noyori, J. Am. Chem. Soc., 110, 629 (1988); H. Kawano, Y. Ishii, M. Saburi, and Y. Uchida, $J$. Chem. Soc., Chem. Commun., 87 (1988).

5. E. Chiellini and G. Galli, Makromol. Chem. Rapid Commun., 4, 285 (1983); E. Chiellini and G. Galli, Macromolecules, 18, 1652 (1985); E. Chiellini, R. Po, S. Carrozzino, and G. Galli, Mol. Cryst. Liq. Cryst., 179, 405 (1990). 